\title{
Smoking among patients in the primary health care system in Nuuk, Greenland
}

\author{
Aya E Reiss ${ }^{1}$, Michael Lynge Pedersen ${ }^{2,3}$ \\ 1. Department of Pediatrics, University of Washington, Seattle, Washington, U.S.A. 2. Greenland Center for Health \\ Research, Institute of Nursing and Health Science, University of Greenland, Nuuk, Greenland. 3. Queen Ingrid Health Care \\ Center, Nuuk, Greenland.
}

Correspondence: Aya E Reiss. Address: 4800 Sand Point Way NE 359300 OC.7.830 Seattle, WA 98105 U.S.A. Email: areiss@u.washington.edu

Received: May 6, 2014

Accepted: July 26, $2014 \quad$ Online Published: September 10, 2014

DOI : $10.5430 /$ cns.v2n4p74

URL: http://dx.doi.org/10.5430/cns.v2n4p74

\section{Abstract}

Background: Tobacco use is the largest preventable cause of death in the developed world. Registration of smoking status in the health care setting has been internationally recognized as an important step towards promoting smoking cessation. Tobacco smoking is highly prevalent in Greenland. However, no studies to date have described the use of smoking cessation interventions in Greenland.

Objective: The purpose of this study is to assess the extent to which smoking status registration was recorded for patients in Nuuk, Greenland over a thirty-month study period. Additionally, smoking prevalence among patients within the same time frame was estimated.

Design: The study was performed as an observational cross-sectional register study based on a review of the electronic medical record for all patients in Nuuk $\geq 18$ years old.

Method: Smoking status registration for all patients at Queen Ingrid Health Care Center between January 1st 2011-June 15th, 2013 was identifed using a search module in the electronic medical record. Proportion of smokers and non-smokers was determined among the registered population using the population in Nuuk as baseline. Quitting rates were calculated for patients with more than one smoking status registration.

Results: Among the population in Nuuk, $15.9 \%$ had smoking status registered during the study period. Smoking prevalence was calculated as $50.7 \%$. During the study period, $10.6 \%$ of the study population who were smokers quit smoking.

Conclusion: The implementation of smoking status registration as an intervention to promote smoking cessation can be performed even in a small, geographically isolated population such as Greenland. While smoking status registration is used as a tool in the clinical setting in Nuuk, opportunities remain to increase the frequency of registration. Smoking prevalence among the study population was less frequent than previously reported among the general population.

\section{Key words}

Smoking, Primary care center, Smoking status, Electronic medical record, Registration, Point-prevalence_abstinence 


\section{I ntroduction}

Tobacco use is the largest preventable cause of death in the developed world. As a result, the world health organization (WHO) has adopted a global agenda for smoking cessation using evidence-based tobacco control measures, starting with monitoring tobacco use ${ }^{[1]}$. Logically, in order to implement smoking cessation interventions, smokers must first be identified. While national efforts at accumulating tobacco use information via census data have been slow to emerge, primary health care providers are perfectly positioned to gather this data ${ }^{[1,2]}$. Prevention and management of morbidity are a vital element of any primary care practioner's agenda ${ }^{[2]}$. Despite this fact, registration of smoking status is still infrequently gathered in the primary care setting ${ }^{[3]}$. A 2010 study in Great Britain showed that only $26 \%$ of patients seeing a new GP had their smoking status registered. While this number improved to $74 \%$ over time, lack of initial registration represents underutilized chances for intervention ${ }^{[4]}$. Similarly, a 2006 study from the United States showed that only $68 \%$ of patients had their smoking status registered ${ }^{[5]}$. While, on average, $2 \%-3 \%$ of all patients will quit smoking independently, physician advice can almost double quitting rates. More intensive advice may result in slightly higher rates of quitting ${ }^{[3,6,7]}$.

Focus on smoking cessation in primary health care is especially relevant in Greenland. Although the use of cigarettes has been reduced within the last 20 years, the prevalence of smokers was last recorded as $66 \%$ of adults in Greenland ${ }^{[8,9]}$. High smoking prevalence exists despite government implementation of high tobacco taxes, restrictive tobacco laws and multiple public anti-smoking campaigns ${ }^{[10]}$. Therefore, in addition to continued national efforts, the need for primary health care system involvement is evident. Furthermore, as a geographically wide-spread small population with a shortage of healthcare professionals, Greenland provides an excellent case study for implementation of smoking cessation interventions in small indigenous populations.

In 2011, the primary health care system in Greenland initiated a lifestyle project focusing on general prevention and quality of care among patients with diabetes, hypertension and chronic obstructive lung disease within the system. The lifestyle project replaced a three year national diabetes project addressing primary care for patients with diabetes mellitus ${ }^{[11,12]}$. As an important part of the lifestyle project, smoking prevention and cessation have been recognized as necessary components of patient health to address in the clinic. Increased awareness of smoking status was introduced in 2011. However, no studies have reviewed the medical records to determine the extent of strategy utilization. Furthermore, the actual prevalence of smokers among patients in Nuuk is unknown. The aim of this register study was to assess the extent to which smoking status registration was recorded for patients in Nuuk during the first thirty months of the intervention, as well as to estimate the smoking prevalence among patients within the same time interval.

\section{Methods}

The study was performed as an observational cross-sectional register study based on data available in the electronic medical record (EMR) used in the primary health care system in Greenland.

\subsection{Setting}

Greenland is the largest island in the world covering an area of over two million $\mathrm{km}^{2}$. The country is only sparsely populated with approximately 56,000 inhabitants living widely spread along the coasts. Around one quarter of the population lives in the capital, Nuuk ${ }^{[13]}$. All inhabitants in Nuuk are served with primary health care at Queen Ingrid Health Care Center (QIHCC). Service, including medications, is free of charge to all inhabitants with permanent addresses. All health care services are documented in the EMR.

\subsection{Awareness of smoking}

During the study period, all health care providers were encouraged to ask and register smoking habits with each patient encounter. Three basic questions were introduced: 1) Do you smoke? 2) On average, how many cigarettes do you smoke 
on a daily basis? 3) Have you ever considered quitting smoking? Any positive thoughts about quitting smoking were praised and, additionally, written or oral information on smoking cessation was provided to each patient who requested.

\subsection{Data collection}

Between the period of January 1st, 2011 and June 15th, 2013, all adult patients $\geq 18$ years of age with at least one registration of smoking status were identified using a search module in the EMR. Demographic data including age and gender were also collected. The average number of cigarettes smoked on a daily basis (cigarettes per day) is recorded in a special field in the EMR. Non-smokers are recorded with zero cigarettes per day. The first and last, if applicable, date of each smoking status registration were extracted for each patient. Anyone with any number of cigarettes per day greater than zero was recorded as a smoker in this study, while those with zero were documented as non-smokers. Observation time between first and last smoking status registration was calculated in days by subtracting the dates of each registration.

The mean age of males and females included in this study was calculated with standard deviation and compared using a two-sample equal variance t-test. Check for normality was done with a Q-Q plot. The overall prevalence of smoking status registration of patients was calculated using the population in Nuuk as it was on January 1st, 2012 as a baseline ${ }^{[14]}$. Prevalence of smokers and non-smokers was also calculated among the registered study population and on the basis of gender. Additionally, for the subset of patients in this sample with more than one registration of smoking status, the proportion of patients who had smoked but then quit smoking and those who had never smoked and started smoking were calculated. Proportions of males and females in each category were compared using Chi-Square Test. $p$-value $<0.05$ was used as a level of statistical significance. Finally, the observation time between first and last smoking status registration was assessed. The median observation time for all patients with two smoking status registrations was calculated as well as for all smokers and quitters alone. All analyses were carried out using SPSS 22.0 and Microsoft Excel.

\section{Results}

The number of people in Nuuk in the middle of this study period was 12,294, of whom 1,957 had smoking status registered during the study period. While there were 5,757 females and 6,537 males in Nuuk, only 1,142 female and 815 males had their smoking status registered. Table 1 shows that the proportion of the entire population with smoking status registration noted in the EMR in this study was $15.9 \%$. There were a significantly higher number of females, $19.8 \%$, than males, $12.5 \%$, registered. On average, the patients in this study were 51 years (standard deviation [SD] 13, 95\% confidence interval [CI] $+/-0.8$ ) with male participants being slightly, but significantly, older than females (average age male participants 53, SD 13, CI 0.9; average age female 49, SD 14, CI 0.8, $p<0.001$ ).

Table 1. Prevalence of smoking practices among patients in study grouped by entire study population and by gender.

\begin{tabular}{llllllll}
\hline & All patients & & Females & & Males & \multicolumn{2}{c}{-value } \\
\hline Smoking registration & $1,957 / 12,294$ & $15.9 \%$ & $1,142 / 5,757$ & $19.8 \%$ & $815 / 6,537$ & $12.5 \%$ & $<0.001$ \\
Smokers & $992 / 1,957$ & $50.7 \%$ & $601 / 1,142$ & $52.6 \%$ & $391 / 815$ & $48.0 \%$ & 0.04 \\
Smoking quitters & $38 / 355$ & $10.6 \%$ & $16 / 211$ & $7.5 \%$ & $22 / 144$ & $15.1 \%$ & 0.02 \\
\hline
\end{tabular}

Note. Fractions represent proportions of actual patients studied during this study period. Percentages are calculated based on proportions. $p$-values obtained by calculating Chi-Square values for each smoking practice by gender and comparing actual and expected frequencies.

As per Table 1, 50.7\% of the study population were noted to be smokers throughout the study period. A significant and slightly higher proportion of smokers in the study were females. There were 673 patients in the study who had smoking status registered more than once. Among these patients, 355 were smokers at the start of the study. Thirty-eight, or $10.6 \%$ (CI 7\%-14\%) of these individuals quit smoking during the study period as represented by a change in registration status from any number of cigarettes to zero. As per Table 1, a significantly higher percentage of these quitters were males. There was no significant difference between the ages of those patients who quit smoking and those who did not (average age 
quitters 52, SD 12, CI 4; average age non-quitters 55, SD 11, CI 1, $p=0.08$ ). At the same time, $3.5 \%$ of the 318 patients who were non-smokers at the start of the study were noted to start smoking on a subsequent registration. This sample represented a greater, but not significant, percentage of female non-smokers than male non-smokers $(5.1 \%$ vs. $1.9 \%, p=$ 0.1). A review of the medical record revealed that 10 out of 11 of these patients were noted in clinical records to be relapsed former smokers.

The median observation time for all patients in this study with more than two smoking status registrations was 256 days (interquartile range 93-476 days). Among the patients with multiple registrations who were smokers, this value was slightly less at 243 days (interquartile range 95-465 days). Finally, for patients who were smokers and quit smoking, this observation time was also slightly shorter at 212 days (interquartile range $92-415$ days).

\section{Discussion}

Smoking status registration provides an excellent opportunity for general practitioners to identify patients at risk of tobacco-related morbidity and mortality and to provide smoking cessation support as necessary. As $15.9 \%$ of all patients in the study area had smoking status registered during the 30-month trial period, our results indicate that this new system is used, with more women than men in particular being registered. Overall smoking rates in the community in this study are slightly lower than per prior report $(50.7 \%$ vs. $66 \%){ }^{[8]}$. From the results of this study, we would hope to be cautiously optimistic about the benefits of logging smoking status on promoting smoking cessation in Greenland.

The frequency of tobacco use documentation in our study is only slightly lower than initial documentation rates noted in other studies. Prevalence of recorded smoking status has been found to be as high as $68 \%-75 \%$ of patients in the US and Great Britain ${ }^{[4,5]}$ and yet initial findings were much lower in the British Study (26\%). While a smaller and more isolated population, Greenland benefits from a structured medical system which can serve to standardize care. Additionally, implementation of this initiative is not technically complicated and also not expensive. Barriers in recording smoking status are well documented, such as limited time in clinic, providers lacking training, and perception of low quitting success rates ${ }^{[15]}$. Numerous studies support that increased training and education of health care providers results in greater monitoring of smoking status and implementation of smoking cessation interventions ${ }^{[15-18]}$. It stands to reason therefore that registration of smoking status has the potential to follow similar trends in Greenland as seen elsewhere.

It was also found that more women than men had smoking status registered, likely related to the fact that women seek health care consultation more frequently and more often in relation to long term health care issues than men ${ }^{[19]}$. Higher rates of females seeking medical care have been found in particular in the local population in Nuuk ${ }^{[20]}$. As approximately $83 \%$ of the overall population in Nuuk has been found to seek medical care in any one year ${ }^{[20]}$, many opportunities for continued monitoring of smoking use remain. Additionally, it is encouraging given that other interventions, such as the national diabetes care program, have been able to make headway and bring change to the health of Greenlandic populations $^{[21]}$.

Smoking rates among the registered patient population are lower than those previously reported in the general population ${ }^{[8]}$. This is in accordance with the reported overall downward trend during the last 20 years in Greenland ${ }^{[8,9]}$. With regards to the frequency of quitting smoking, this study found much higher rates than observed elsewhere. While we observed $10.6 \%$ of the study population quit smoking during the trial, rates noted in the most recent Cochrane review on the subject in 2013 would predict an average of only 6\% smoking cessation with only brief advice interventions being performed, such as in this study ${ }^{[6]}$. This $6 \%$ assumes a spontaneous quit rate of $2 \%-3 \%$ with an additional $1 \%-3 \%$ increase based on advice intervention. Although spontaneous quit rates are not known for Greenland, a Danish study found only $1 \%$ spontaneous smoking cessation rates ${ }^{[22]}$. In evaluating these results, it is encouraging to see such high quite rates but it is also important to note that our study only captures two points in time. We are deeming all patients who went from any number of cigarettes to zero cigarettes in the study period as successful quitters. It would be ideal to track these patients 
over longer, more consistent periods of time to determine if quitting rates persist in a more permanent fashion beyond point-prevalence documentation. While the common standard for monitoring smoking cessation for patients is to follow up at 6 and 12 months ${ }^{[23]}$, this was an observational study. Our median observation time was $>6$ months and therefore a control trial assessing this intervention on a patient to patient basis would help to address long-term cessation rates. This is further reflected by the fact that $3.5 \%$ of the patient study population were noted to start smoking during the study period but in fact almost exclusively represented relapsed smokers. Estimated 1 year relapse rates are typically $10 \%{ }^{[16]}$. Therefore we suspect rates of prolonged abstinence to be lower than quitting rates noted in our point-prevalence study. We did observe that men had higher quitting rates than women, consistent with other studies that find similar gender differences in smoking cessation ${ }^{[24]}$. The decision to quit smoking is multifactorial ${ }^{[25]}$ and would be difficult to contribute to one sole intervention. Regardless of the reduction in smoking rates noted in our study, prevalence in Greenland remains higher than international average, indicating that focus on smoking cessation is still quite important.

\section{Strengths and limitations of the study}

One of the major strengths of this study is that it reflects the entire population in Nuuk. Although our sample size is small, every patient recorded in the medical record was evaluated and therefore we can be quite confident that smoking status registration and smoking prevalence accurately reflect current trends. Additionally, this study is the first to describe smoking cessation interventions in the primary health care system in Greenland. At the same time, this study does have a number of limitations. As an observational study, without any control group, conclusions regarding smoking status registration and smoking quitting rates are simply correlations as we are not able to assess causality. Further, observation time was not structured for each individual patient. As a result, data represent only point-prevalence abstinence, making it more difficult to discern prolonged abstinence from pre-relapse rates. However, our median observation time was greater than 6 months. Finally, it is important to note that smoking status in this study was based on patient self-reporting to health care providers. A 1999 study from Australia demonstrated that patients were more likely to report inaccurate smoking status when asked by a non-physician to report smoking habits ${ }^{[26]}$. Therefore the number of non-smokers and quitters in this study might be overrepresented. However, the majority of studies assessing smoking status use patient report as opposed to biochemical validation as a primary outcome measure ${ }^{[6]}$.

\section{Conclusions}

The primary health care system in Greenland faces severe logistical challenges delivering health care to a small but widely geographically spread population. In addition, shortage of educated health care professionals and financial limitations remain on-going challenges with health care implementation and interventions. Smoking status registration has potential and is used in Nuuk, but opportunities remain to increase the frequency of registration. Overall, smoking prevalence is still very high although decreased compared to earlier findings for the general population. Given the relatively high amount of registrations documented in this study, we feel these findings represent an implementable intervention. Continued focus on tobacco use limitation initiatives are recommended.

\section{Acknowledgement}

The authors acknowledge the help of Anna Raske Lynge and Jytte Lindskov Jacobsen in preparing the data.

\section{Conflict of interest}

The authors have no conflicts of interest.

\section{References}

[1] World Health Organization. WHO report on the global tobacco epidemic, 2013: enforcing bans on tobacco advertising, promotion and sponsorship: executive summary. Geneva, Switzerland. 2013. 
[2] Vardavas CI, Symvoulakis EK, Lionis C. Dealing with tobacco use and dependence within primary health care: time for action. Tob Induc Dis. 2013; 11(1): 6. PMid:23442803 http://dx.doi.org/10.1186/1617-9625-11-6

[3] Coleman T. ABC of smoking cessation. Cessation interventions in routine health care. BMJ. 2004; 328:631-633. PMid:15016697 http://dx.doi.org/10.1136/bmj.328.7440.631

[4] Szatkowski L, Lewis S, McNeill A, Coleman T. Is smoking status routinely recorded when patients register with a new GP? Fam Pract. 2010; 27(6): 673-675. PMid:20624749 http://dx.doi.org/10.1093/fampra/cmq046

[5] Ferketich AK, Khan Y, Wewers ME. Are physicians asking about tobacco use and assisting with cessation? Results from the 2001-2004 national ambulatory medical care survey (NAMCS). Prev Med. 2006; 43(6): 472-476. PMid:16920185 http://dx.doi.org/10.1016/j.ypmed.2006.07.009

[6] Stead LF, Buitrago D, Preciado N, Sanchez G, Hartmann-Boyce J, Lancaster T. Physician advice for smoking cessation. Cochrane Database Syst Rev. 2013; (5): CD000165. PMid:23728631.

[7] Wittchen HU, Hoch E, Klotsche J, Muehlig S. Smoking cessation in primary care - a randomized controlled trial of bupropione, nicotine replacements, CBT and a minimal intervention. Int J Methods Psychiatr Res. 2011; 20(1): 28-39. PMid:21574208 http://dx.doi.org/10.1002/mpr.328

[8] Bjerregaard P, Becker U. Validation of survey information on smoking and alcohol consumption against import statistics, Greenland 1993-2010. Int J Circumpolar Health. 2013; 72: 10. PMid:23471142 http://dx.doi.org/10.3402/ijch.v72i0.20314

[9] Bjerregaard P, Aidt EC. Life Conditions, lifestyle and health - population surveys in Greenland 2005-2009. (Danish and Greenlandic). Copenhagen; University of Southern Denmark. 2010.; 1-30p. PMid:21158956.

[10] Government of Greenland. Inatsisartutlov nr. 15 af 26. maj 2010 om forbud mod rygning (smoking restriction law 2010). (Danish and Greenlandic) [Internet]. Available from:

http://naalakkersuisut.gl/da/Naalakkersuisut/Departementer/Sundhed-og-Infrastruktur/Sundhedslovgivning

[11] Pedersen ML. Diabetes mellitus in Greenland. Dan Med J. 2012 Feb; 59(2): B4386. Review.

[12] Damsgaard L, Pedersen ML. Use of glycosylated haemoglobin as diagnostic tool in Greenland: prevalence of diagnosed diabetes mellitus. Diabetol Metab Syndr. 2013 Oct 9; 5(1): 59.

[13] Greenland briefly. Nuuk: Grønlands selvstyre departement for boliger, infrastruktur og trafik. (Danish)[Internet]. [cited 2011 November 2]. Available from: http://www.climategreenland.gl/

[14] Greenland statistic. Population in Greenland. [internet]. [cited 2013 June 20]. Available from: http://www.stat.gl/default.asp?lang=en.

[15] Verbiest ME, Crone MR, Scharloo M, Chavannes NH, van der Meer V, Kaptein AA, et al. One-Hour Training for General Practitioners in Reducing the Implementation Gap of Smoking Cessation Care: A Cluster-Randomized Controlled Trial. Nicotine Tob Res. 2013. [Epub ahead of print]. PMid:23873981.

[16] Hughes J, Peters EN, Naud S. Relapse to smoking after 1 year of abstinence: A meta-analysis. Addict Behav. 2008; 33(12): 1516-20. PMid:18706769 http://dx.doi.org/10.1016/j.addbeh.2008.05.012

[17] Anderson P, Jane-Llopis E. How can we increase the involvement of primary health care in the treatment of tobacco dependence? A meta-analysis. Addiction. 2004; 98: 299-312. PMid:14982543 http://dx.doi.org/10.1111/j.1360-0443.2003.00672.x

[18] Carson KV, Verbiest ME, Crone MR, Brinn MP, Esterman AJ, Assendelft WJ, et al. Training health professionals in smoking cessation. Cochrane Database Syst Rev. 2012; (5): CD000214. PMid:22592671

[19] Briscoe ME. Why do people go to the doctor? Sex differences in the correlates of GP consultation. Soc Sci Med. 1987; 25(5): 507-513. http://dx.doi.org/10.1016/0277-9536(87)90174-2

[20] Pedersen ML, Rolskov A, Jacobsen JL, Lynge AR. Frequent use of primary health care service in Greenland: an opportunity for undiagnosed disease case-finding. Int J Circumpolar Health. 2012 Jul 24;71: 18431.

[21] Pedersen ML, Jacobsen JL. Improvement of diabetes care in a small but geographically widely spread population in Greenland. Effects of a national diabetes care programme. Diabetic Medicine. 2011; 28(11): 1425-1432. PMid:21615488 http://dx.doi.org/10.1111/j.1464-5491.2011.03337.x

[22] Bredesen H, Lous J. Rygeafvænning. Ugeskr læger. 2009; 171(9): 683-688. PMid:19257992.

[23] West R, Hajek P, Stead L, Stapleton J. Outcome criteria in smoking cessation trials: proposal for a common standard. Addiction. 2005; 100(3): 299-303. PMid:15733243 http://dx.doi.org/10.1111/j.1360-0443.2004.00995.x

[24] Perkins KA. Smoking cessation in women. Special considerations. CNS Drugs. 2001; 15(5): 391-411. PMid:11475944 http://dx.doi.org/10.2165/00023210-200115050-00005

[25] Gallus S, Muttarak R, Franchi M, Pacifici R, Colombo P, Boffetta P, et al. Why do smokers quit? Eur J Cancer Prev. 2013; 22(1): 96-101. PMid:22644233 http://dx.doi.org/10.1097/CEJ.0b013e3283552da8

[26] Schofield PE, Hill DJ. How accurate is in-patient smoking status data collected by hospital admissions staff? Aust N Z J Public Health. 1999; 23(6): 654-656. http://dx.doi.org/10.1111/j.1467-842X.1999.tb01555.x 